\title{
ANALISIS PERILAKU IBU TENTANG CUCI TANGAN DENGAN KEJADIAN DIARE PADA BALITA DI RUMAH SAKIT MARDI RAHAYU KUDUS
}

\author{
Ilham Setyobudi ${ }^{1}$, Fitri Pribadiani ${ }^{2}$, Anita Dyah Listyarini ${ }^{3}$ \\ ${ }^{1,2,3}$ Prodi S1 Keperawatan STIKES Cendekia Utama Kudus \\ Email : anitadyahlistyarini@gmail.com
}

\begin{abstract}
ABSTRAK
Diare merupakan salah satu masalah kesehatan di Indonesia.Diare merupakan penyebab kematian nomor dua pada balita, nomor tiga pada bayi dan nomor lima bagi sejumlah umur. Berdasarkan kelompok umur, penderita diare terbanyak pada kelompok umur 1-5 tahun. Banyak faktor yang menyebabkan diare pada balita salah satunya adalah perilaku ibu. Tercatat ada 461 balita yang terkena diare pada tahun 2018 dan setiap tahunnya mengalami peningkatan.Tujuan dalam penelitian ini untuk mengetahui adakah hubungan perilaku ibu tentang cuci tangan dengan kejadian diare pada balita Metode: Jenis penelitian ini adalah desfriptif corelatif dengan rancangan cross sectional. Populasi yang di pergunakan berjumlah 82 dengan menggunakan teknik accidental sampling. Penggumpulan data menggunakan alat ukur kuesioner.Metode analisa data menggunakan uji chiquare. PenelitiAan dilakukan di Ruang Anak Rumah Sakit Mardi Rahayu Kudus dari akhir Maret sampai dengan akhir April 2019. Hasil menunjukkan bahwa terdapat hubungan antara perilaku ibu tentang cuci tangan dan kejadian diare pada balita $(p=0,000<0,05)$. Simpulan: Dengan mengunakan analisa chi square diperoleh hasil bahwa nilai $\mathrm{P}$ value nya 0,000 . Jadi menurut standar dalam analisa kesehatan jika nilai $\mathrm{P}$ value $<0,05$ berarti memiliki hubungan.
\end{abstract}

Kata Kunci : Perilaku ibu, balita, kejadian diare

\begin{abstract}
Diarrhea is one of the health problems in Indonesia. Diarrhea is the number two cause of death in infants, number three in infants and number five for a number of ages. Based on age group, most diarrhea patients in the age group 1-5 years. Many factors cause diarrhea in infants, one of which is maternal behavior. There were 461 children under five who were affected by diarrhea in 2018 and each year has increased. Research purposes : To find out is there a relationship between mother's behavior about hand washing with the incidence of diarrhea in infants. Method : This type of research is correlative descriptive with cross
\end{abstract}


sectional design. The population used is 82 using accidental sampling technique. Data collection using a questionnaire measuring instrument. Methods of analyzing data using the chi-quare test. The study was conducted in the Children's Room of Mardi Rahayu Kudus Hospital from the end of March to the end of April 2019. Results: The results showed that there was a relationship between maternal behavior about hand washing and the incidence of diarrhea in infants ( $p=0,000$ $<0,05)$. Conclusion: By using chi square analysis, the results show that the $P$ value is 0,000. So according to the standards in health analysis if the value of $P$ value $<0.05 m e a n s$ having arelationship.

Keywords : Mother's behavior, toddlers, diarrhea 


\section{LATAR BELAKANG}

Diare adalah terjadinya peningkatan frekuensi buang air besar lebih dari tiga kali dalam sehari dan konsistensi feses menjadi cair. Diare dapat digolongkan menjadi diare akut atau bila telah berlangsung lebih dari dua minggu dikategorikan sebagai diare kronik. Penyebab terjadinya diare, dapat disebabkan oleh multifactorial contohnya seperti infeksi, malabsorbsi, pencemaran makanan, daya tahan tubuh yang rendah, kondisi lingkungan dan sebagian besar disebabkan oleh infeksi. Diare juga dapat disebabkan karena kurangnya pengetahuan ibu tentang diare, perilaku kebersihan yang buruk, serta air minum yang tidak sehat. Penyakit diare merupakan suatu masalah yang sering terjadi di dunia (Anas,W.G.A., \& Listyarini,A.D, 2014).

Diare juga merupakan penyebab kedua kematian pada balita setelah pneumoni, terutama pada negara berkembang. Menurut UNICEF (United Nations Children's Fund ) dan WHO (World Health Organization) pada 2009 diare merupakan penyebab kematian normor dua pada balita di dunia, nomor 3 pada bayi, dan nomor 5 bagi segala umur. Data UNICEF memberitahukan bahwa 1,5 juta anak meninggal dunia setiap tahunnya karena diare. Penyakit diare masih merupakan masalah kesehatan masyarakat di Indonesia, baik ditinjau dari angka kematian serta kejadian luar biasa (KLB) yang ditimbulkan. Pada tahun 2015, diare menyebabkan sekitar 688 juta orang sakit dan 499.000 kematian di seluruh dunia tejadi pada anak-anak dibawah 5 tahun. Data WHO (2017) menyatakan, hampir 1,7 miliar kasus diare terjadi pada anak dengan angka kematian sekitar 525.000 pada anak balita tiap tahunnya. Prevalensi tertinggi terdapat pada balita usia 12-23 bulan. Diare lebih sering pada laki-laki (14,8 \%) dibandingkan dengan anak perempuan $(12,5 \%)$.

Diare pada anak yang merupakan diare akut sebanyak 85\%, 10\% diare berlanjut, dan $5 \%$ diare persisten. Proporsi kasus diare yang ditangani di Jawa Tengah tahun 2017 sebesar 55,8 \%, menurun bila dibandingkan proporsi tahun 2016 yaitu 68,9 \%. Pada Tahun 2017 dari 911.901 kejadian diare 95.635 dapat tertangani. Persentase kasus diare yang ditangani menurut data dari kabupaten tahun 2017 yaitu 43,2 \% .Pada tahun 2016 memang agak lebih tinggi sedikit presentasenya yaitu 45,2 \%.Sedangkan angka kejadian diare di Rumah Sakit Mardi Rahayu Kudus pada tahun 2017 adalah 452 dan di tahun 2018 adalah 461 dengan angka kematian pada tahun 2017 yaitu 1 dan pada tahun 2018 adalah 3 kejadian.

Menurut pendapat peneliti sesuai dengan fakta dan teori yang ada, bahwa diare dapat disebabkan oleh beberapa faktor salah satu nya yakni faktor perilaku. Hal tersebut dikarenakan kesehatan seseorang dipengaruhi oleh perilaku yang dilakukannya. Perilaku itu sendiri menurut teori dipengaruhi oleh beberapa faktor yakni faktor dari dalam diri, faktor pendukung, dan yang terakhir faktor penguat untuk terwujudnya suatu perilaku (Listyarini, 2020). Perilaku positif atau negatif sangat bergantung dari ketiga faktor tersebut.

Menurut data yang kami peroleh dalam kurun waktu 1 tahun angka kejadian diare pada anak-anak di ruang anak-anak sekitar 156 kejadian. Berdasarkan hasil wawancara oleh peneliti kepada sepuluh ibu pasien yang anaknya dirawat dengan diare ada tujuh ibu yang mengatakan bahwa cuci tangan itu yang penting ada air 
dan sabun yang untuk cuci tangan (Riyanto, A, 2018). Mereka tidak mengetahui cara yang benar untuk melakukan cuci tangan. Sehingga mereka selama ini hanya mencuci tangannya yang penting bersih tidak memikirkan tentang prosesur atau cara yang benar melakukan cuci tangan supaya kuman-kuman yang menempel hilang. Disini peneliti ingin meneliti tentang perilaku ibu tentang cuci tangan dengan kejadian diare pada balita di rumah sakit dengan bentuk penelitian kuantitatif dengan metode penelitian korelasi yaitu menghubungkan dua variable dalam satu waktu. Dengan pendekatan cross sectional menggunakan total sampling dengan jumlah responden 82 dan penggumpulan data dengan kuesioner dengan menggunakan analisis statistis chi square.

\section{METODE PENELITIAN}

Jenis penelitian deskreptif corelatif dengan rancangan cross sectional. Pada penelitian ini peneliti mencoba untuk mencari hubungan variable bebas (Perilaku ibu tentang cuci tangan) dengan variable terikat ( Kejadian diare) yang analisanya menentukan ada tidaknya hubungan antara variable. Rancangan cross sectional merupakan rancangan penelitian dengan melakukan pengukuran atau pengamatan pada saat bersamaa (sekali waktu) antar variable bebas dan variable terikat. Penelitian ini akan dilakukan di Ruang Anak Rumah Sakit Mardi Rahayu Kudus. Waktu penelitian Bulan akhir Maret- akhir April 2019. Populasi dalam penelitian ini adalah semua pasien balita 0-5 tahun yang terkena diare yang di rawat di RS Mardi Rahayu dengan jumlah pasien 461 anak yang rawat inap selama tahun 2018. Dari jumlah populasi balita yang terkena diare sejumlah 461, maka jumlah sampel yang digunakan adalah 82. Metode yang digunakan pengambilan sampel adalah Accidental sampling. Teknik accidental sampling yaitu pengambilan sampel secara aksidental (accidental) dengan mengambil kasus atau responden yang kebetulan ada atau tersedia di suatu tempat sesuai dengan konteks penelitian

\section{HASIL DAN PEMBAHASAN}

Tabel 1 Distribusi frekuensi pengetahuan ibu tentang cuci tangan di Ruang anak RS. Mardi Rahayu bulan Maret 2019 ( $\mathrm{N}=82$ )

\begin{tabular}{ccc}
\hline Pengetahuan & Frekuensi & Presentasi (\%) \\
\hline Baik & 49 & 59,8 \\
Sedang & 33 & 40,2 \\
Kurang & 0 & 0 \\
\hline Total & 82 & 100 \\
\hline
\end{tabular}

Dari 82 responden yang peneliti ambil ada 49 orang ibu yang mempunyai pengetahuan baik, jadi sekitar 59,8\% dari total responden yang ada.

Tabel 2 Distribusi frekuensi sikap ibu tentang cuci tangan di Ruang Anak RS. Mardi rahayu bulan Maret 2019 ( $\mathrm{N}=82$ )

\begin{tabular}{ccc}
\hline Sikap & Frekuensi & Presentasi (\%) \\
\hline Baik & 74 & 90,2 \\
Sedang & 8 & 9,8 \\
Kurang & 0 & 0 \\
\hline Total & 82 & 100
\end{tabular}


Dari tabel diatas dapat dijelaskan bahwa ibu yang memiliki sikap cuci tangan yang baik ada $90,2 \%$ ada 74 orang ibu .

Tabel 3 Distirbusi frekuensi tindakan ibu tentang cuci tangan di Ruang Anak RS. Mardi rahayu bulan Maret 2019 ( $\mathrm{N}=82$ )

\begin{tabular}{ccc}
\hline Tindakan & Frekuensi & Presentasi (\%) \\
\hline Baik & 63 & 76,8 \\
Sedang & 19 & 23,2 \\
Kurang & 0 & 0 \\
\hline Total & 82 & 100 \\
\hline
\end{tabular}

Dari tabel diatas dapat dijelaskan untuk tindakan cuci tangan ibu yang baik adalah 63 orang jika di presentasikan ada $76,8 \%$ ibu yang telah melakukan cuci tangan yang baik.

Tabel 4 Distribusi frekuensi perilaku ibu tentang cuci tangan di Ruang Anak RS. Mardi Rahayu bulan Maret 2019 ( $\mathrm{N}=82$ ).

\begin{tabular}{ccc}
\hline Tindakan & Frekuensi & Presentasi (\%) \\
\hline Baik & 52 & $63,4 \%$ \\
Sedang & 30 & $36,6 \%$ \\
Kurang & 0 & 0 \\
\hline Total & 82 & 100
\end{tabular}

Perilaku ibu tentang cuci tangan dilihat dari data tabel ada $63,4 \%$ baik dan yang sedang adalah $36,6 \%$ sedangkan yang berperilaku kurang tidak ada.

Tabel 5 Distribusi frekuensi kejadian diare pada balita di Ruang AnakRS.Mardi Rahayu bulan Maret 2019 ( $\mathrm{N}=82$ )

\begin{tabular}{ccc}
\hline Kejadian Diare & Frekuensi & Presentasi (\%) \\
\hline Tidak & 52 & $63,4 \%$ \\
Ya & 30 & $36,6 \%$ \\
\hline Total & 82 & 100
\end{tabular}

Berdasarkan hasil penelitian diatas pengetahuan, sikap dan praktik ada hubungannya dengan angka kejadian diare pada balita. Dalam tiga domain tersebut dikompositkan menjadi perilaku,sehingga perilaku ibu tentang cuci tangan memang ada hubungannya dengan kejadian diare. Di lihat dari data penelitian diatas $59,8 \%$ ibu yang mempunyai pengetahuan baik ,90,8\% mempunyai sikap yang baik dan $63,4 \%$ mempunyai praktik yang baik. Dengan hasil demikian kita bisa lihat datri hasil data kejadian diare ada $63,4 \%$ anakyang tidak mengalami diare berulang. Dengan menggunakan uji chi square diperoleh nilai $\mathrm{p}$ valuenya 0,000 berarti jika nilai $\mathrm{p}$ value kurang dari 0,05 maka ada hubungan.

\section{PEMBAHASAN}

\section{Analisa Univariat}

Dari hasil penelitian menunjukkan bahwa sebagian besar ibu balita mempunyai pengetahuan yang baik ada 49 orang ibu (59,8\%), yang memiliki sikap yang baik terhadap cuci tangan ada $90,2 \%$ dan yang memiliki tindakan baik sebanyak 76,8\%. Ibu memiliki pengetahuan cuci tangan yaitu dari membaca atau memperoleh penyuluhan di kelompok-kelompok kecil seperti PKK, Posyandu atau penyuluhan yang diadakan di balai desa tentang cuci tangan. Ada juga yang memperoleh infomasi dari media televise atau dari media sosial bahkan ada yang dari hobi membacanya sehingga ibu ini tahu tentang pentingnya cuci tangan.Dan 
tidak hanya itu saja ada juga yang sudah mengetahui langkah cuci tangan yang benar, yang baru digalakkan pemerintah dalam Germas.

Menurut teori yang peneliti baca dari Notoadmodjo (2010) pengetahuan itu adalah hasil dari tahu dan ini terjadi setelah seseorang melakukan penginderaan suatu objek. Pengetahuan atau kognitif merupakan suatu hal yang penting dalam membentuk tindakan seseorang. Pengetahuan merupakan domain yang sangat penting dalam membentuk tindakan seseorang (overt behavior). Dari pengalaman penelitian tertulis bahwa perilaku yang didasari oleh pengetahuan akan lebih langgeng dari pada perilaku yang tidak didasari oleh pengetahuan Menurut penelitian yang dilakuakan Dyah Ragil dan yunita Dyah.2017 bahwa pengetahuan tentang cuci tangan memang ada hubungannya dengan kejadian diare Karena bisa memutuskan mata rantai penularan. Menurut peneliti bahwa dalam memperoleh sikap dan tindakan yang baik itu ada peran serta dari pengetahuan.

Pengetahuan ibu dapat dipengaruhi oleh faktor lainnya seperti umur dan pengalaman. Umur ibu tergolong masih muda, mengakibatkan kurang pengalaman tentang perilaku cuci tangan yang baik agar mencegah penyakit. Oleh karena itu, penting bagi ibu untuk meningkatkan pengetahuan tentang mencuci tangan agar terhindar dari kuman penyakit dengan membaca melalui media internet, media massa maupun mengikuti seminar dan menanyakan dengan petugas kesehatan tentang cuci tangan yang baik dan benar (2018, 2017). Pengetahuan yang didapat seorang ibu melalui media sosial, televise atau bahhkan dari media massa terkadang berbeda-beda tetapi tidak menutup kemungkinan ada yang sama atau ada sedikit perbedaan sehingga ibu dalam melakukan cuci tangan belum benar-benar bisa melakukan cuci tangan sesuai dengan standart yang sebenarnya.

Informasi yang demikian terkadang membuat ibu tidak mau mempraktikkan cuci tangan dengan benar karena sumber informasi yang masih dikatakan belum tentu kebenarannya, sehingga ibu-ibu yang mempunyai pengalaman di suatu tempat atau mungkin pada waktu anaknya dirawat tentunya akan bertanya tentang tindakan cuci tangan yang benar (Listyarini, 2020). Masalah yang timbul dari pengetahuan yang diterima setengah-setengah akan mengakibatkan ibu kurang merespon dengan baik tentang pengetahuan yang di peroleh, sehingga dalam bersikap maupun bertindak ibu juga masih bisa di kategorikan kurang.

Pengetahuan memang memegang peran penting dalam terbentuknya sikap dan praktik yang baik. Maka dari itu perlu sekali edukasi secara berulang-ulang sehingga dapat benar-benar dipahami, karena jika hanya ,melihat informasi dari media sosial ataupun membaca dari media cetak tentunya kurang mengena. Dengan adanya sarana edukasi tau pendidikan kesehatan yang dilakukan oleh baigian terkait bisa tepat sasaran. Menurut Kemenkes RI (2013), bahwa sekitar 30 penelitian terkait menemukan bahwa mencuci tangan yang benar dapat memangkas angka penderita diare hingga separuh. Hal tersebut tidak sejalan dengan hasil penelitian oleh Wardani et al (2017) yang menyatakan bahwa tidak ada hubungan antara pengetahuan mencuci tangan yang benar dengan tingkat kejadian diare.

Hasil dalam penelitian ini juga menunjukkan masih banyaknya responden yang sudah tahu tentang cara mencuci tangan tetapi masih terkena penyakit diare. 
Hal ini dipengerahui oleh sikap dan tindakan yang kurang baik. Responden yang sudah memilki pengetahuan baik tentang cara mencuci tangan belum mengaplikasikannya dalam kehidupan sehari-harinya. Intinya bahwa tidak selamanya pengetahuan akan berubah menjadi sikap dan sikap akan menjadi tindakan (Notoatmodjo, 2011).

\section{Analisa Bivariat}

Hasil penelitian tentang perilaku ibu tentang cuci tangan dengan kejadian diare adalah $63,4 \%$ dari ibu yang mempunyai perilaku baik tidak mengalami diare berulang dan ibu yang mempunyai perilaku kurang ada 36,6\% yang mengalami diare berulang ada sekitar 30 orang ibu.Menurut teori peneliti baca dari Ali,2010 dan Notoadmojo,2010. Perilaku adalah respon atau reaksi individu terhadap stimulasi yang berasal dari luar atau dari dalam dirinya.Perilaku adalah segenap manifestasi hayati individu dalam berinteraksi dengan lingkungan, mulai dari perilaku yang paling nampak sampai yang tidak tampak, dari yang dirasakan sampai paling yang tidak dirasakan (Okviana, 2015).Perilaku merupakan hasil daripada segala macam pengalaman serta interaksi manusia dengan lingkunganya yang terwujud dalam bentuk pengetahuan, sikap dan tindakan. Sedang menurut jurnal-jurnal yang peneliti baca sebagai dasar penelitian ini banyak mengemukaan antara perilaku cuci tangan dan kejadian diare itu relevan atau dengan kata lain adalah ada hubungannya walahpun prosentase nya lain-lain. Dilihat dari angka kejadian diare selama kurun waktu 1 bulan penelitian kurang lebih ada 85 kejadian akan tetapi diare yang dialami tidak serta merta dikarenakan perilaku keluarga kurang baik, namun ada beberap faktor pencetus diare lainnya.

Menurut jurnal yang peneliti baca hasil sesuai dengan yang peneliti lakukan bahwa perilaku ibu tentang cuci tangan ada hubungannya dengan kejadian diare pada balita , semakin baik perilaku cuci tangan maka akan semakin rendah angka kejadian diare.(Retno purwandari,2013). Beberapa hasil riset menunjukkan bahwa promosi perilaku mencuci tangan, peningkatan kualitas air bersih dan sanitasi lingkungan telah terbukti mengurangi kejadian penyakit gastrointestinal, penyakit pernapasan dan menurunkan absensi murid pada negara berkembang (Chittleborough, et al, 2013).Penelitian serupa yang dilakukan oleh Luby, et al(2009), mengatakan bahwa cuci tangan dengan sabun secara konsisten dapat mengurangi diare dan penyakit pernapasan. Cuci tangan pakai sabun (CTPS) dapat mengurangi diare sebanyak $31 \%$ dan menurunkan penyakit infeksi saluran nafas atas (ISPA) sebanyak 21\%.Rabbi dan Dey (2013), mengatakan bahwa kesenjangan antara pengetahuan mencuci tangan dengan praktik cuci tangan masih berlanjut, untuk itu diperlukan inisiatif jangka panjang untuk menyadarkan masyarakat terutama pada ibu dan anak pentingnya cuci tangan pakai sabun (CTPS). Pengenalan CTPS sudah dilakukan sejak lama, namun praktik di masyarakat masih rendah, terutama pada anak-anak cuci tangan pakai sabun masih sering diabaikan, sehingga kegiatan untuk mempromosikan CTPS perlu terus dilakukan sebagai upaya meningkatkan kesadaran pada masyarakat yang di khususkan pada anak-anak. 


\section{SIMPULAN DAN SARAN}

\section{Simpulan}

Setelah dilakukan penelitian kurang lebih 1 bulan lamanya di Ruang Anak Rumah Sakit Mardi rahayu didapatkan ibu yang mempunyai perilaku baik 63,4\% dan hasil dari anak-anak yang tidak mengalami diare berulang sekitar 63,4\% juga. Hasil dari uji statistic chi square adalah nilai $\mathrm{p}$ valuenya $=0,000$,jadi jika nilai $\mathrm{p}$ value $<0,005$ maka dapat dikatakan ada hubungan antara perilaku ibu tentang cuci tangan dengan kejadian diare.

\section{Saran}

Diharapkan responden dapat mengali informasi dari mana saja baik yang disampaikan melalui edukasi maupun dari media apa saja. Dilihat dari angka kematian anak-anka yang tinggi disebabkan oleh diare maka perlu edukasi dan praktiik cuci tangan yang berulang-ulang baik keluarga maupun pasien.Untuk peneliti selanjutnya agar dapat mengoservasi praktik ibu tidak hanya saat dirawat inap melainkan saat dirumah juga jadi dapat memantau apakah perilaku cuci tangan tetap diterapkan di rumah atau tidak.

\section{DAFTAR PUSTAKA}

Dyah Ragil WL, Yunita Dyah. Hubungan Antara Pengetahuan Dan Kebiasaan Mencuci Tangan Pengasuh Dengan Kejadian Diare Pada Balita Jurnal of Health Education ISSN 2527-4252.

Dr. Drs. Sutanto Priyo Hastanto, M.Kes.(2016). Analisa Data Pada Bidang Kesehatan.

Departemen Kesehatan RI.(2011).Situasi Diare di Indonesia. Jakarta: Departemen Kesehatan RI.

Enikmawati,A.\&Aslamah,F.H.2017. Hubungan Antara Perilaku Cuci TanganDengan Kejadian Diare Pada Anak Sd. Motorik Jurnal IlmuKesehatan(JournalOfHealthScience),12(25).(online:http://ejournal.stikes m kla.ac.id/index.php/motor/article/view/312, diakses pada 1 oktober 2017).

Erich. (2007). Konsep Dasar Diare. Jakarta: Salemba Medika

Gracia Risnawaty. Faktor Determinan Perilaku Cuci Tangan Pakai Sabun(CTPS) Pada Masyarakat Di Tanah Kali Kediding. Jurnal Promkes, Vol. 4, No. 1 Juli 2016: 70-81

Hardi. (2012). Faktor-faktor Yang mempengaruhi Kejadian Diare Pada Balita di Wilayah Kerja Puskesmas Baranglompi Kecamatan Ujung Tanah. Makassar: Skripsi Fakultas Kesehatan Masyarakat Universitas Hasanuddin

Hajar, I. (2013). Faktor-Faktor Yang Berhubungan Dengan Kejadian Diare Pada Balita Di Desa Mattiro Dolangeng Wilayah Puskesmas LiukangTupabbiring Kabupaten Pangkep. Makassar: Skripsi Fakultas Kesehatan Masyarakat Universitas Hasanuddin

I Gusti Made Geria Jelantik, I Gusti Ayu Rai Astarini. (2015). Hubungana Pengetahuan, Sikap Dan Ketersediaan Sarana Dengan Kebiasaan Cuci Tangan Pakai Sabun Untuk Mencegah Diare Dan Ispa Pada Ibu Rumah Tangga Di Kelurahan Ampenan Tengah Kota Mataram. 
Listyarini, A. D., \& Fatmawati, Y. (2020). Edukasi Gizi Ibu Hamil Dengan Media Booklet Tentang Perilaku Pencegahan Balita Stunting Di Wilayah Puskesmas Undaan Kabupaten Kudus. Jurnal Ilmu Keperawatan dan Kebidanan, 11(1), 100-105.

I Wayan Arimbawa, Komang Ayu Trisna Dewi, Zakwan bin Ahmad. (2014). Hubungan Faktor Perilaku dan Faktor Lingkungan Terhadap Kejadian Diare Pada Balita di Desa Sukawati, Kabupaten Gianyar Bali. ISM, Vol. 6 NO.1, Mei-Agustus, HAL.ISSN 2089-9084

Juffrie. (2011). Gastroenterologi-Hepatologi, jilid 1. Jakarta: Badan penerbit IDAI

Kemenkes RI 2013. Profil Kesehatan Indonesia. Ditjen P2P Kemenkes RI

Kelana kusuma Dharma : TIM, (2011). Metodologi PenelitianKeperawata (Pedoman Melaksanakan dan Menerapkan Hasil Penelitian ).

Notoatmodjo, S. (2012). Metodologi Penelitian kesehatan. Jakarta: Rineka Cipta

Rosidi, A, Handarsari, E., Mahmudah, M. (2010). Hubungan Kebiasaan Cuci Tangan dan Sanitasi Makanan dengan Kejadian Diare Pada Anak SD Negeri Podo 2 Kecamatan Kedungwuni Kabupaten Pekalongan. Jurnal Kesehatan Masyarakat. Vol 6. No 1. Hal 76-84. September 2010.

Rabbi, E.S \& Dey, N.C. (2013). Exploring the gap between handwashing knowledge and practice in Bangladesh, a cross-sectional comparative study. BMS Public Health. Vol 13:89. Pages 2-7

Rachmayanti. 2013. Penggunaan Media Panggung Dalam Pendidikan Personal Hygiene Cuci Tangan Menggunakan Sabun di Air Mengalir.(Online:www.journal.unair.ac.id/filerPDF/1.\%20Penggunaan\%20 Med\%20Panggung\%20Boneka.pdf, diakses tanggal 1 Oktober 2017)

Rauf, H. (2013). Hubungan Pengetahuan, Sikap Dan Perilaku Ibu Terhadap Derajat Kejadian Diare Pada Balita Di Puskesmas Pattalassang Kabupaten Takalar. Makassar: Skripsi Fakultas Kesehatan Masyarakat Universitas Hasanuddin.

Tutut Sulistiyowati 1, Rini Hayu Lestari 2. (2017). Perilaku Ibu Tentang hygiene Makanan Dengan kejadian Diare Pada Balita Di Desa Bareng Jombang.

Wawan, A. 2010. Teori dan Pengukuran Pengetahuan, Sikap, dan Perilaku Manusia. Yogyakarta: Nuha Medika

Wong, D. (2009). Buku Ajar Keperawatan Pediatrik, volume 1. Jakarta: Buku Kedokteran EGC

Anas, W. G. A., \& Listyarini, A. D. (2014). Hubungan Pengetahuan Siswa Tentang PHBS (Perilaku Hidup Bersih dan Sehat) Tatanan Sekolah dengan Kejadian Diare di SD Sari I Kecamatan Gajah Kabupaten Demak. Jurnal Keperawatan dan Kesehatan Masyarakat Cendekia Utama, 3(2).

Riyanto, A., \& Listyarini, A. D. (2018). Hubungan Perilaku Phbs Rumah Tangga Dengan Kejadian Ispa Pada Balita Di Desa Tanjung Rejo Kecamatan Jekulo Kudus. Prosiding HEFA (Health Events for All), 2(2). 